\title{
Nonpolitical Versus Political Participation: Longitudinal Associations with Mental Health and Social Well-Being in Different Age Groups
}

\author{
Matthias Lühr ${ }^{1}$ (D) Maria K. Pavlova ${ }^{1}$ (D) Maike Luhmann²
}

Accepted: 4 August 2021 / Published online: 18 August 2021

(c) The Author(s) 2021

\begin{abstract}
Drawing on public opinion and empirical research, one may advise people to participate in voluntary organizations because voluntary participation can improve their mental health and social well-being. However, do such benefits apply across different types of participation and across the life course? In this study, we investigated whether benefits to mental health and social well-being differ between nonpolitical and political participation and across age groups (preregistration is accessible at https://osf.io/kqcbe). Using 25 waves of data from the British Household Panel Survey and the Understanding Society (1991-2016), we conducted multilevel analyses with observations nested within participants in younger $(14-29, n=10,536)$, middle-aged $(40-50, n=4,955)$, and older $(65-75, n=3,059)$ adults. We used life satisfaction and GHQ-12 scores as measures of mental health, and social support and neighborhood belonging as measures of social well-being. We found only few and small significant effects at the within-person level: On occasions when younger adults reported political participation, they reported slightly higher neighborhood belonging than when they did not. On occasions when older adults reported nonpolitical or political participation, they reported slightly higher life satisfaction than when they did not. However, we found no significant differences between nonpolitical and political participation and among age groups. In sum, our findings qualify the opinion that voluntary participation yields significant benefits to engaged individuals. We discuss potential explanations, including characteristics of political participation in the United Kingdom.
\end{abstract}

Keywords Civic and political engagement $\cdot$ Life course $\cdot$ Mental health · Social capital · Volunteering

Matthias Lühr

matthias.luehr@uni-vechta.de

Institute of Gerontology, University of Vechta, Driverstr. 23, 49377 Vechta, Germany

2 Faculty of Psychology, Ruhr University Bochum, Universitätsstr. 150, 44780 Bochum, Germany 


\section{Introduction}

Voluntary organizations in the United Kingdom seek to recruit participants by emphasizing the benefits of participation to engaged individuals (Community Works, n.d.; Health Education England, 2017). For instance, they maintain that volunteering improves mental health-as reflected in higher levels of life satisfaction, positive emotions, or self-esteem, and lower levels of psychological distress (Manwell et al., 2015; World Health Organization, 2018) — and fosters social well-being (Keyes, 2006), such as social integration and support (Community Works, n.d.; Health Education England, 2017). Researchers have generally agreed that participants in formal organizations that contribute to a common benefit (e.g., helping others, changing social or political conditions) may feel particularly meaningful, valued, and socially embedded because they are integrated into a structured social network and join like-minded companions to benefit others (Almedom, 2005; Berkman et al., 2000; Ferlander, 2007; Piliavin \& Siegl, 2015; Verba et al., 1995). Indeed, many studies found that voluntary participation or formal volunteering-doing unpaid work for voluntary organizations (Morrow-Howell, 2010)—was related to better mental health and higher social well-being, particularly among older adults (for reviews, see Anderson et al., 2014; Douglas et al., 2017; Piliavin \& Siegl, 2015; Wilson, 2012; Xue et al., 2020).

Are these conclusions straightforward? Consider a member of a voluntary organization who has disputes with or feels alienated from others, and whose attempts to benefit the community are neither effective nor widely appreciated. We would not expect such a person to experience substantial benefits from their voluntary participation (cf. Umberson \& Montez, 2010; Villalonga-Olives \& Kawachi, 2017). Although the degree of benefits certainly depends upon individual experiences, we argue that type of participation may play a role. Political scientists (Theiss-Morse \& Hibbing, 2005; Verba et al., 1995) differentiated between nonpolitical participation (i.e., in organizations that aim to help others directly) and political participation (i.e., in organizations that strive to change social or political conditions). As attempts to exert political influence involve intergroup conflicts and unachieved goals and are sometimes regarded as morally reprehensible and selfish (Pavlova et al., 2021), political participation may not be as beneficial to engaged individuals as nonpolitical participation is. In support of this assumption, several studies found stronger mental health and social well-being benefits for participation in religious or human service organizations than in environmental organizations, political parties, or political movement groups (Albanesi et al., 2007; Croezen et al., 2015; Vinson \& Ericson, 2014; Yeung et al., 2018; but see Mazhari, 2015; Talò et al., 2014).

Moreover, whether one benefits from nonpolitical or political participation depends on their needs and life situation (Okun \& Schultz, 2003; Piliavin \& Siegl, 2015). Socioemotional selectivity theory (Carstensen et al., 1999) posits that individuals with a broad time perspective (e.g., younger adults) are future-oriented and focus on gaining knowledge and enlarging their social network, whereas individuals who perceive their future time as limited (e.g., older adults) seek immediate emotional comfort and more personal social interactions. Take for example a meeting of an environmental organization on which ideas on how to influence environmental policy are exchanged. Participants have the opportunity to meet other participants, to deliver a speech, or to moderate discussions. Younger adults may be more likely than older adults to perceive such opportunities as beneficial to their future and the working life because they can make useful contacts with influential individuals (Ruiter \& De Graaf, 2009) and develop social skills, such as expressing oneself and applying conflict resolution strategies (Verba et al., 1995). Older adults may be bothered 
by potential disagreements and tiring discussions that have no influence on actual politics. However, working in organizations that aim at directly helping (i.e., nonpolitical organizations) may provide immediate emotional gratification and social integration for older adults as they have less conflict potential and emphasize harmonic social ties (Theiss-Morse \& Hibbing, 2005). These ideas were partly supported in longitudinal analyses of the German Socio-Economic Panel (SOEP), which found that for older adults $(65+)$, nonpolitical volunteering was associated with higher life satisfaction and lower loneliness, whereas political volunteering had the opposite effects on these outcomes (Lühr et al., 2021). There were no significant associations in younger age groups.

We are not aware of any other study that distinguishes among the effects of different types of participation in different age groups; as such, whether these findings from Germany can be generalized to other sociopolitical contexts is questionable. In liberal welfare states (e.g., the Unites States, the United Kingdom; Esping-Andersen, 1990), individualism and pluralism are strongly valued and social welfare spending is low, while rates of political participation are typically high (Beauregard, 2014; Esping-Andersen, 1990; Spicker, 2013). In a recent UK survey, $61 \%$ of respondents reported to have participated in at least one activity to influence political decisions, laws, or policies in the previous 12 months (Hansard Society, 2019). Higher national rates of political participation may indicate its greater social acceptance, whereas low social welfare spending may make participants in nonpolitical voluntary organizations feel particularly needed (Hansen et al., 2018; HaskiLeventhal, 2009). In this context, both nonpolitical and political participation may yield more benefits across age groups than elsewhere.

In this study, we tested the effects of nonpolitical and political participation on mental health and social well-being and age differences therein in a UK sample. We used panel data from the British Household Panel Survey (BHPS; 1991-2008) and its continuation, the Understanding Society (UndSoc; 2010 onwards). Prior BHPS studies used a global measure of volunteering or voluntary participation and found positive longitudinal effects on life satisfaction and GHQ-12 scores (Barbieri, 2017; Binder, 2015; Binder \& Freytag, 2013; Fiorillo et al., 2017; Giordano \& Lindström, 2011; Lawton et al., 2020; Winters \& Rundlett, 2014), particularly among older adults (Tabassum et al., 2016). These findings are in line with those of many other studies that investigated the benefits of volunteering (for general reviews, see Anderson et al., 2014; Piliavin \& Siegl, 2015; for longitudinal studies on age differences, see Musick \& Wilson, 2003; Van Ingen \& Kalmijn, 2010; Van Willigen, 2000). However, using global measures of volunteering implicitly assumes that all types of participation are similar.

In this paper, we took a more differentiated perspective by distinguishing different types of participation across the life course. Moreover, in contrast to most prior BHPS studies, we used a corrected BHPS dataset, ${ }^{1}$ included more recent data from the UndSoc, and investigated effects not only on mental health (i.e., life satisfaction, GHQ-12 scores) but also on social well-being (i.e., perceived social support, neighborhood belonging). Social support was a frequently used outcome of voluntary participation in prior research (though not in the BHPS-based studies; Anderson et al., 2014; Pilkington et al., 2012). However, hardly any research has considered neighborhood belonging as an outcome. Voluntary participation may foster neighborhood belonging because it often occurs at the community level and

\footnotetext{
1 In previous editions of the BHPS data release, information on frequency of volunteering in 2008 was wrong (i.e., it was copied from another leisure activity). The data release we used in the present study (11th edition) contained corrected data. We used the volunteering variable in supplementary analyses.
} 
may attach people to places and communities (Berkman et al., 2000; Russell et al., 2019). In a meta-analysis, Talò et al. (2014) found an average correlation of 0.36 between voluntary participation and sense of community, a psychological construct that encompasses feelings of belongingness to, mattering in, and being emotionally connected to a community (McMillan \& Chavis, 1986). Nevertheless, pertinent research has usually assumed higher sense of community to promote voluntary participation rather than the other way round (Talò et al., 2014).

To answer the question whether an individual experiences improvements in mental health and social well-being if they participate in nonpolitical and political organizations (within-person associations), it is not sufficient to conduct between-person analyses that compare different individuals to each other. Such analyses only indicate whether individuals with higher and lower rates of voluntary participation differ with regard to their mental health and social well-being. In contrast, within-person associations are less likely to be confounded by self-selection of individuals with higher levels of mental health and social well-being into voluntary participation (Dawson-Townsend, 2019; De Wit et al., 2015; Hamaker \& Muthén, 2020; Lawton et al., 2020). De Wit and colleagues (2015) concluded that about $75 \%$ of the well-being differences between volunteers and non-volunteers can be attributed to selection effects. Recently, researchers have increasingly addressed the within-person associations between voluntary participation and well-being and found modest effects at best (Bjälkebring et al., 2021; Dawson-Townsend, 2019; De Wit et al., 2015; Fiorillo et al., 2017; Lawton et al., 2020; Lühr et al., 2021; Meier \& Stutzer, 2008). Therefore, it is important to examine within-person associations separately from between-person differences, which is possible when longitudinal data from multiple measurements are available.

For this purpose, we conducted multilevel analyses with observations nested within participants (Wang \& Maxwell, 2015). To test for age differences, we compared the subsamples of younger (16-29), middle-aged (40-50), and older (65-75) adults (for preregistration of methods and hypotheses, see https://osf.io/kqcbe). We hypothesized nonpolitical participation to have more positive effects on mental health and social well-being than political or semipolitical participation has (Hypothesis 1). By semipolitical participation, we refer to participation in organizations (e.g., environmental organizations) that typically include both a nonpolitical (e.g., removing plastics from water) and a political agenda (e.g., protesting against plastic bag production). With regard to age differences, we expected the positive effects of nonpolitical participation on mental health and social well-being to be stronger in older than in younger and middle-aged adults (Hypothesis 2) but the effects of political or semipolitical participation to be more negative, the older the participants are (Hypothesis 3).

\section{Method}

\subsection{Sample and Procedure}

The BHPS, which ran from 1991 to 2008, was a representative yearly panel survey of adults $(16+)$ residing in private households in the United Kingdom (Taylor et al., 2010). The BHPS was partly continued in the UndSoc (2010, onwards). We used combined data from the BHPS and the UndSoc (1991-2016; University of Essex, 2019) and selected only subsamples from the BHPS that are representative of the UK general population (Great 
Britain main sample 1991, Scotland extension 1999, Wales extension 1999, Northern Ireland extension 2001). We divided participants into three contrasting age groups that represent distinct life stages with different goals and obligations: 16-29-year-olds (late adolescents and emerging adults who prepare for labor market entry), $n=10,536 ; 40-50$-year-olds (middle-aged adults, typically with work and family commitments), $n=4,955$; and 65-75-year-olds (older adults, most of whom are in retirement), $n=3,059$. The assignment to age groups was based on participants' mean age between the first and last year of participation. These age groups were time invariant so participants did not change or leave their respective age groups, even if their age on a given occasion was below or exceeded the initial age limit. For descriptive statistics of predictor and outcome variables, see Table 1 (for full descriptive statistics, see online Appendix A).

\subsection{Measures}

\subsubsection{Voluntary Participation}

In the BHPS and the UndSoc, frequency of volunteering ("We are interested in the things people do in their leisure time... Tell me how frequently you do each one... Do unpaid voluntary work"; 1-5) and active participation in various voluntary organizations ("Whether you are a member or not, do you join in the activities of any of these organisations on a regular basis?"; $0=$ no, $1=$ yes) were assessed as part of different modules that rotated yearly (i.e., they were never administered in the same wave). As only the measures for active participation (assessed 13 times between 1991 and 2014) differentiated between types of organizations, we used these measures for our main analyses. In supplemental analyses, we checked whether using the measure of global volunteering as a predictor would lead to substantially different findings. Across age groups, correlations between active participation in any voluntary organization and frequency of volunteering in the following wave ranged from 0.30 to 0.35 . Autoregressive correlations of frequency of volunteering (2-year lag) ranged from 0.54 to 0.59 . Thus, in spite of some overlap between active participation and volunteering, the two measures were not equivalent.

To group voluntary organizations into nonpolitical and political participation, we looked into each organization type and scanned the activities mentioned at the prominent websites of exemplary organizations for nonpolitical and political agendas. Ultimately, we coded participation in "voluntary service groups" and "religious groups or church organizations" as nonpolitical participation $(0=$ no, $1=$ yes $)$, because activities in such organizations usually involve direct helping but no attempts at policy change (e.g., organizing charities for people in need; Yeung et al., 2018). We coded participation in "political parties," "environmental groups," "parent/school associations," "residents' groups/neighborhood watch," "women's institutes," "feminist organizations," "pensioners' organizations," "other community or civic groups," "trade unions," and "professional organizations" as political or semipolitical participation $(0=$ no, $1=$ yes $)$, because many such organizations try to influence political decision-making, among other things. For instance, more than half of the people affiliated with women's rights, professional, neighborhood, or political party organizations affirmed that their organization takes a stance on political issues (Verba et al., 1995).

However, these organizations certainly differ in their agendas. Therefore, in supplementary analyses, we differentiated among political parties, work-related political organizations ("trade unions," "professional organizations"), organizations that represent an 


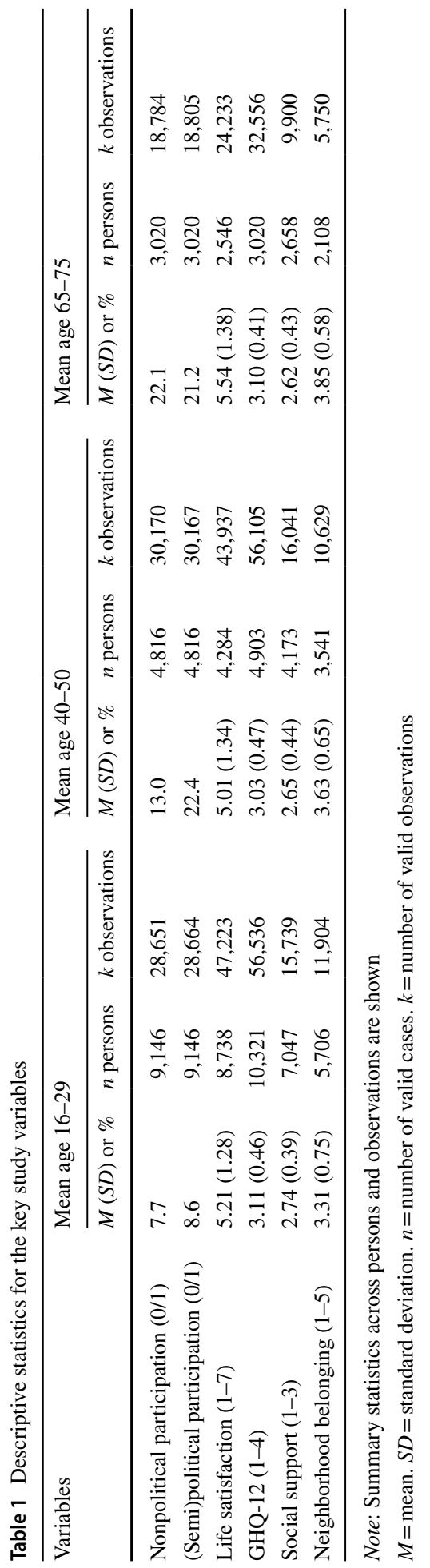


extension of other roles ("parent/school associations," "residents' groups/neighborhood watch," "pensioners' organizations"), and other semipolitical organizations ("environmental groups," "women's institutes," "feminist organizations," "other community or civic groups").

\subsubsection{Mental Health}

In every wave, the $G H Q-12$, which is a broad measure of mental health that assesses feelings of strain, depression, self-efficacy, and self-esteem, was administered (Goldberg \& Williams, 1988). Respondents rated the GHQ-12 items on a 4-point scale (e.g., "Have you recently been losing confidence in yourself?" $1=$ not at all, $2=$ no more than usual, $3=$ rather more than usual, $4=$ much more than usual; $\alpha=0.86-0.91$ across waves). In every year since 1996 (except 2001), general life satisfaction was assessed with one item: "How satisfied or dissatisfied are you with your life overall?" $(1=$ not satisfied at all; $7=$ completely satisfied). The rating scale in the UndSoc had slightly different wording but the same range, compared to the rating scale of the BHPS. As mental health is a state of well-being that goes beyond the absence of mental disorders (World Health Organization, 2018), life satisfaction (i.e., a component of hedonic well-being) may be considered as a mental health indicator (Lombardo et al., 2018; Manwell et al., 2015).

\subsubsection{Social Well-Being}

Seven times between 1991 and 2007, five items assessed perceived social support (e.g., "Is there anyone who you can really count on to help you out in a crisis?"; for previous use, see Gray, 2009). Moreover, five times between 1998 and 2014, neighborhood belonging was assessed with eight items (e.g., "I feel like I belong to this neighbourhood"; $1=$ strongly disagree; $5=$ strongly agree; $\alpha=0.84-0.88$ across waves; for previous use, see Li et al., 2005). We used this measure of neighborhood belonging as an operationalization of sense of community.

\subsubsection{Control Variables}

We controlled for the known potential confounders of the link between voluntary participation and mental health/social well-being (cf. Anderson et al., 2014; Piliavin \& Siegl, 2015; Thoits \& Hewitt, 2001): sociodemographics (sample origin for region, sex, age, highest academic qualification, employment status, equivalized disposable household income in Euros [logged], occupational status, cohabiting with a partner/spouse, and living with underage children in the household), life events (loss events, other life events), health (oneitem measure of subjective health, number of hospital stays in the past year), and other leisure activities (church attendance, participation in sport and leisure organizations, caregiving). Furthermore, we controlled for the source of the data with a binary survey indicator (BHPS vs. UndSoc).

\subsection{Statistical Approach}

We conducted two-level linear regression analyses with observations nested within participants (Wang \& Maxwell, 2015) in Mplus 8.3. To ensure that within-person coefficients were not confounded with between-person associations, we used uncentered binary predictors 
of nonpolitical and political participation at the within-person level but added their person means (i.e., person-specific rates of participation across all observations) as between-person predictors (Hamaker \& Muthén, 2020). Within-person coefficients obtained from these models provide information on whether individuals reported better or worse mental health and social well-being on the occasions that they reported voluntary participation-compared to the occasions on which they did not report voluntary participation. Hence, they are comparable to those obtained from fixed-effects models (Hamaker \& Muthén, 2020) employed by many recent studies on the outcomes of voluntary participation (Barbieri, 2017; Binder, 2015; Croezen et al., 2015; Fiorillo et al., 2017; Winters \& Rundlett, 2014). In contrast to fixedeffects models, multilevel models estimate between-person differences as well. Although all our hypotheses referred to within-person change, we looked into between-person differences too because they indicate whether participants with higher rates of participation generally report better mental health and higher social well-being, which may point to potential selfselection of such individuals into voluntary participation (Dawson-Townsend, 2019; De Wit et al., 2015; Lühr et al., 2021).

We used four outcome variables: a single item on life satisfaction, the mean score of GHQ12 (inverted such that higher scores represented better mental health), perceived social support, and neighborhood belonging. For each outcome, we tested two models: Model 1 (unadjusted model) included nonpolitical and political participation as predictors at both levels and the binary survey indicator at the within-person level. In Model 2 (adjusted model), we added covariates, which were person-mean centered at the within-person level and grand-mean centered at the between-person level. We focused on the concurrent instead of lagged associations between the time-varying predictors and the outcome variables, because a 1-year lag might be too long for capturing the effects of participation on mental health and social well-being (cf. Dormann \& Griffin, 2015; Lühr et al., 2021). However, we tested for the effects of lagged predictors in supplementary analyses.

As maximum likelihood estimation was computationally infeasible with our very large sample, we used Bayesian estimation and tested all paths in the model for significance using Bayesian credibility intervals (Muthén \& Asparouhov, 2012). Bayesian estimation in combination with multilevel analysis is not compatible with multiple group analysis in MPlus. Therefore, we conducted analyses separately in each age group. Whenever an effect was significant (at $p<0.05)$ in any age group, we used the method of overlapping confidence intervals with a correction suggested by Knol et al. (2011) to test for age differences in this effect. To test for differences between the effects of different variables (i.e., nonpolitical and political participation), we used a $z$-test. We used a more stringent level of significance $(p<0.01)$ for both difference tests to adjust for multiple significance testing. The Bayesian estimator is a full information estimator that uses all available data to estimate parameters but does not impute missing values (Muthén \& Asparouhov, 2012). Full information estimators outperform listwise deletion across missing data mechanisms, particularly for large amounts of missingness (Newman, 2003). To facilitate parameter estimation under missingness, we used missing data covariates at the within-person level (equalized disposable household income and subjective health from the previous wave). 


\section{Results}

\subsection{Within-Person Associations}

In younger and middle-aged adults, nonpolitical and political participation had virtually no significant within-person associations with life satisfaction or GHQ-12 scores (see Table 2; for full regression results, see online Appendix B). On occasions when older adults reported nonpolitical or political participation, they reported significantly-but only slightly-higher life satisfaction than when they did not ( $\beta \mathrm{s}=0.06$ for both nonpolitical and political participation ${ }^{2}$; the difference between those was not significant); but they did not report significantly different GHQ-12 scores. Furthermore, when younger adults reported political participation, they reported slightly higher neighborhood belonging than when they did not $(\beta=0.11)$; this association was not significant for nonpolitical participation $(\beta=0.05$; the difference between political and nonpolitical participation was not significant). In middle-aged and older adults, we found no significant associations between nonpolitical or political participation and social support or neighborhood belonging in adjusted models, although there were isolated significant associations in unadjusted models. For adjusted models, we found no significant age differences in the associations of political or nonpolitical participation with any outcome. Only in unadjusted models was the association between political participation and higher neighborhood belonging significantly more positive in younger than in older adults.

To sum up, Hypothesis 1 was not supported because there were no significant differences between the associations of nonpolitical and political participation with the outcomes. Hypothesis 2 received very limited support: Even though nonpolitical participation was associated with higher life satisfaction only in older adults, there were no associations with other outcomes in older adults, and age differences were not significant. Finally, Hypothesis 3 also received limited support: In unadjusted models, political participation did appear to have a stronger positive association with neighborhood belonging in younger than in older adults, but it was also associated with higher life satisfaction only in older adults (age difference was not significant).

\subsection{Between-Person Associations}

As shown in Table 3, across age groups, individuals with higher average rates of nonpolitical participation generally reported higher average life satisfaction across observations; in adjusted models, this association was significant in middle-aged $(\beta=0.04)$ and older $(\beta=0.06)$ adults. $^{3}$ On the contrary, average rates of political participation were not associated with life satisfaction in adjusted models. Furthermore, average rates of nonpolitical participation were not associated with GHQ-12 scores, but older adults with higher average rates of political participation reported better GHQ-12 scores $(\beta=0.04)$. Individuals with

\footnotetext{
2 As predictors were binary variables, standardized coefficients for within-person associations were calculated by dividing the unstandardized coefficients by the within-person SD of the outcome. In the text, we provide standardized coefficients only for significant associations in fully adjusted models, if not mentioned otherwise. Unstandardized regression coefficients and other statistics are shown in tables.

3 Standardized coefficients for between-person associations were calculated by multiplying the unstandardized coefficients by the between-person SD of the predictor and dividing this term by the between-person $\mathrm{SD}$ of the outcome.
} 


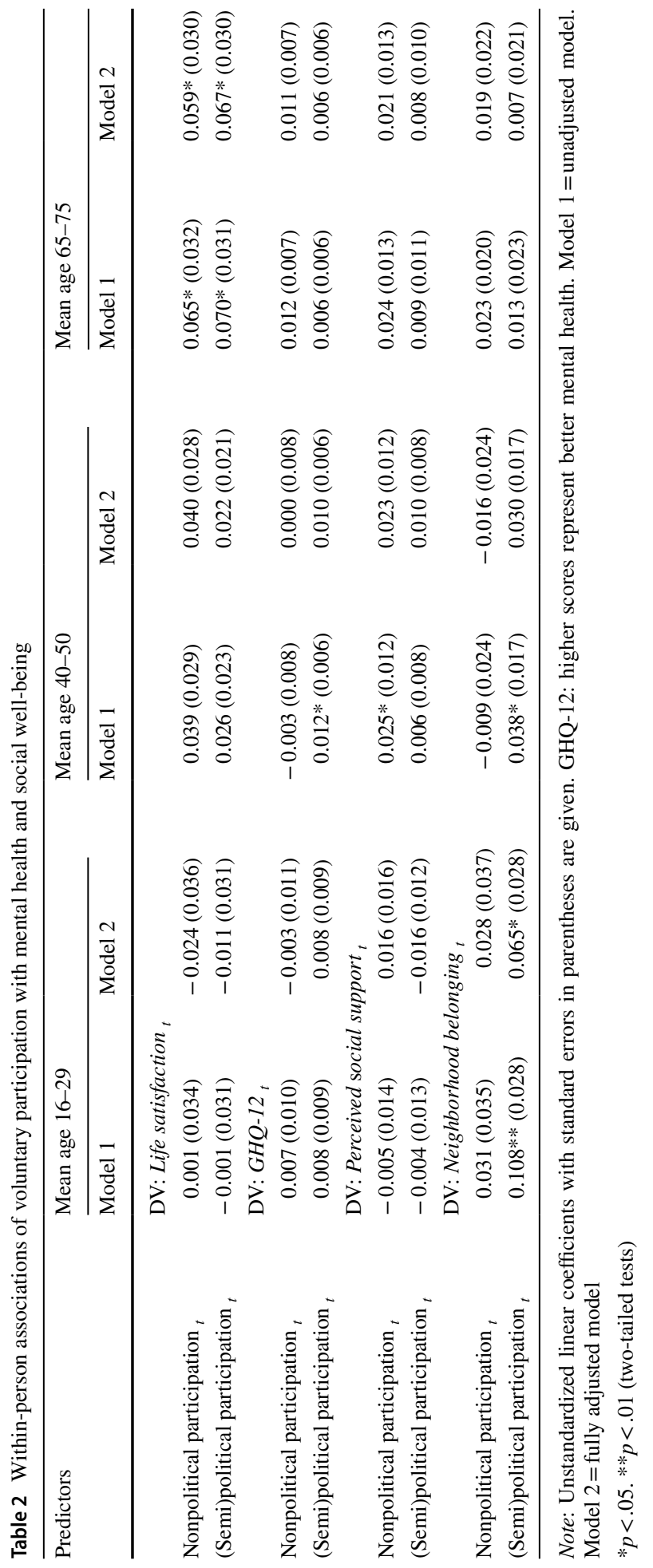




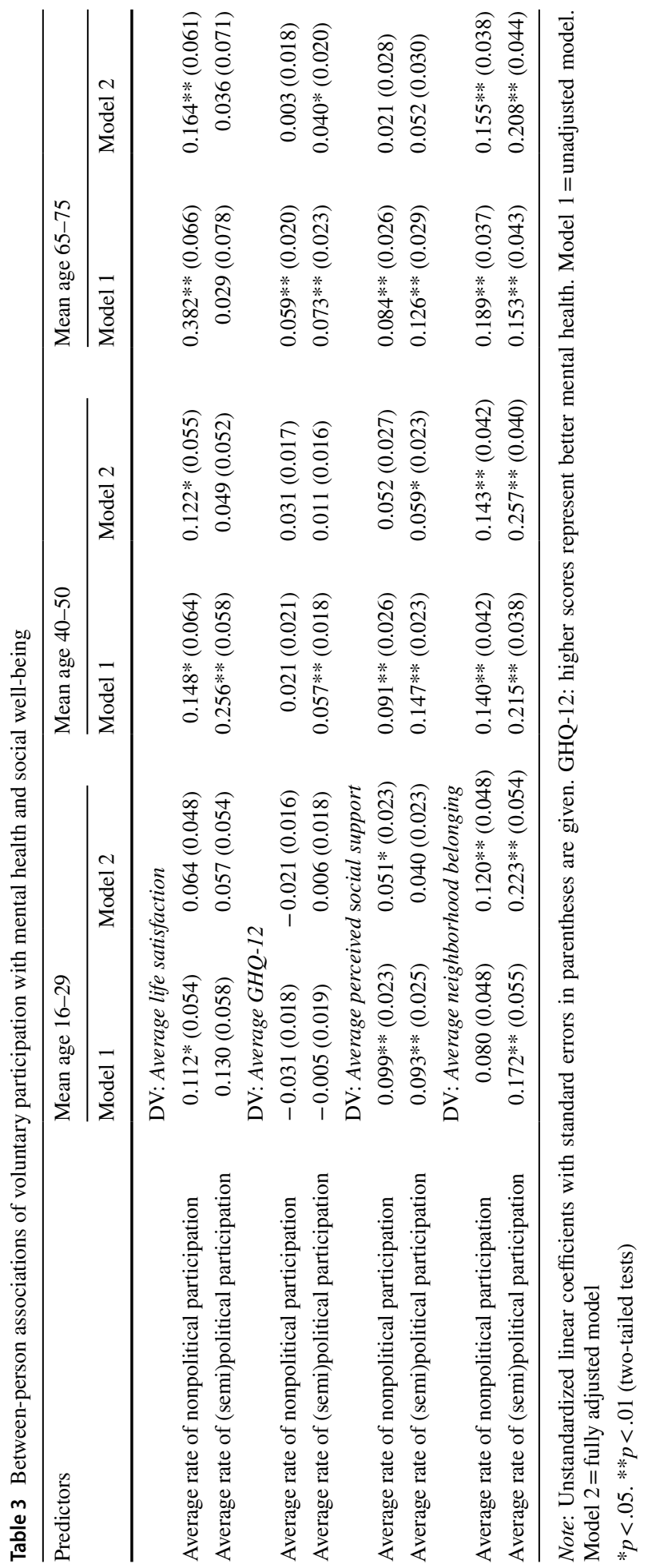


higher average rates of nonpolitical and political participation generally reported higher social well-being. However, for perceived social support, these associations held only for nonpolitical participation in younger adults $(\beta=0.05)$ and political participation in middleaged adults $(\beta=0.05)$ when all covariates had been controlled for. By contrast, the associations with higher neighborhood belonging were consistent across age ( $\beta$ s from 0.06 to $0.15)$.

\subsection{Robustness Checks and Supplementary Analyses}

As within-person associations appeared similar for nonpolitical and political participation, we combined both predictors into one variable that indicated active participation in any voluntary organization $(0=$ no, $1=$ yes; see online Appendix $C)$. On occasions when they participated in any voluntary organization, younger adults reported higher neighborhood belonging ( $\beta=0.13$; only in the unadjusted model); middle-aged adults reported more social support $(\beta=0.06)$; and older adults reported higher life satisfaction $(\beta=0.07)$, better GHQ-12 scores $(\beta=0.05)$, and more social support $(\beta=0.07)$, compared to the occasions when they did not participate in any voluntary organization. Only the within-person association between participation in any voluntary organization and life satisfaction was significantly (at $p<0.01$ ) more positive in older than in younger adults in adjusted models.

Furthermore, we checked whether using volunteering as a predictor instead of voluntary participation would yield substantially different findings. In adjusted models, more frequent volunteering than usual (i.e., compared to the individual mean across observations) was significantly associated with marginally better GHQ-12 scores $(\beta=0.03)$ and higher neighborhood belonging $(\beta=0.04)$ in middle-aged adults and with higher life satisfaction $(\beta=0.02)$, better GHQ-12 scores $(\beta=0.03)$, and higher neighborhood belonging $(\beta=0.04)$ in older adults (see online Appendix D). In sum, using volunteering instead of participation in any voluntary organization as a predictor yielded similar results: no significant effects in younger adults, and occasionally significant but small effects in middle-aged and older adults.

Analyses with four different types of political organizations entered separately as predictors did not suggest that a specific subtype of (semi)political participation was consistently related to better or worse mental health or social well-being (see online Appendix E). Significant associations were mainly positive and emerged particularly for participation in organizations that represent an extension of other roles (i.e., parent, school, neighborhood, or pensioner organizations). Even the presumably most political type of participationparticipation in political parties-was significantly associated with better GHQ-12 scores in older adults and higher neighborhood belonging in younger adults.

Furthermore, we tested for lagged within-person effects of nonpolitical and political participation. We found only one significant effect: Older adults who reported political participation on a given occasion reported higher neighborhood belonging in the next year $(\beta=0.18)$. In addition, we ran analyses with a GHQ-12 score that was based on a bimodal item scoring (e.g., $0=$ rather more than usual, much more than usual; $1=$ not at all, no more than usual; Goldberg \& Williams, 1988). Results were similar to the results reported above. Finally, we used shifted cut-off values for the age groups of younger (20-35), middle-aged (45-60), and older (70-85) adults. Results for younger and middle-aged adults were similar to the results of our main analyses. Older adults reported not only significantly higher life satisfaction but also significantly better GHQ-12 scores and more social support on occasions when they reported political participation. 


\section{Discussion}

Our study contributes to the literature on the benefits of voluntary participation by investigating differences in the effects of nonpolitical and political participation in different age groups. We hypothesized that nonpolitical participation has more positive effects on mental health and social well-being than political participation. Moreover, we hypothesized that older adults benefit more from nonpolitical participation but less from political participation than other age groups. To test these hypotheses, we used large-scale panel data from the United Kingdom and looked into within-person associations of nonpolitical and political participation with life satisfaction, GHQ-12 scores, perceived social support, and neighborhood belonging.

\subsection{Is Nonpolitical Participation More Beneficial than Political Participation?}

Overall, we did not find any significant differences in the within-person associations of nonpolitical and political participation with mental health and social well-being, but-if any-small positive effects of both. Thus, our results do not support the idea that nonpolitical participation is a more benefical type of participation than political participation.

It is possible that political participation in the United Kingdom is less frustrating than it is in other European countries. Benefits of political participation may be greater in countries where it is valued and seen as an opportunity to express one's values and to improve community life (Spicker, 2013). Such notions of political participation may be most prominent in liberal welfare states whose high national rates of political participation may indicate a societal appreciation and an individual desire for participation in politics (Beauregard, 2014; Esping-Andersen, 1990; Spicker, 2013). Notably, positive associations of political participation with mental health and social well-being outcomes also emerged in cross-sectional (Yeung et al., 2018) and longitudinal (Musick \& Wilson, 2003) studies conducted in the United States, another liberal welfare state.

Furthermore, nonpolitical participation did not yield as beneficial effects as we expected. One may argue that voluntary participation improves mental health and social well-being only if it involves volunteering because taking the role of a direct helper-besides its social gratifications that should also pertain to voluntary participation-may help individuals to feel productive and to see a purpose in life (Pavlova \& Silbereisen, 2012; Piliavin \& Siegl, 2015; Son \& Wilson, 2012). However, frequency of volunteering (not differentiated by types of organizations or activities) did not have more or stronger effects on mental health and social well-being in our post-hoc analyses.

Many studies that used a similar methodology to ours (i.e., multilevel or fixed-effects analyses) likewise found small or nonsignificant within-person associations of (nonpolitical) volunteering or voluntary participation with mental health and social well-being (cf. Dawson-Townsend, 2019; De Wit et al., 2015; Fiorillo et al., 2017; Lawton et al., 2020; Lühr et al., 2021; Meier \& Stutzer, 2008). Thus, the associations of voluntary participation with positive outcomes found in cross-sectional studies or in longitudinal studies that did not separate within-person change from between-person differences (for reviews, see Anderson et al., 2014; Morrow-Howell, 2010; Piliavin \& Siegl, 2015; Wilson, 2012; for single longitudinal studies, see Li \& Ferraro, 2005; Musick \& Wilson, 2003; Van Ingen \& Kalmijn, 2010; Van Willigen, 2000) might have partly reflected interindividual differences provoked by self-selection of better adjusted individuals into voluntary participation 
(cf. Lühr et al., 2021; De Wit et al., 2015). Supporting this possibility, our between-person results suggest that, across age groups, individuals with higher life satisfaction are more likely to participate in nonpolitical organizations (cf. Thoits \& Hewitt, 2001), and individuals with higher neighborhood belonging are more likely to participate in any voluntary organization (cf. Talò et al., 2014). To illustrate, participants who reported nonpolitical participation at all observations scored up to $0.18 S D$ higher on life satisfaction and up to $0.30 S D$ higher on neighborhood belonging than those who never reported nonpolitical participation.

In general, the few and small positive within-person associations we found qualify the widespread opinion that voluntary participation improves social support, status, and recognition (Berkman et al., 2000; Ferlander, 2007) and is thus beneficial to mental health. As we investigated effects in a representative sample of the UK general population, our findings speak against voluntary participation as a means of universal prevention of mental health problems (McLaughlin, 2011). However, we cannot rule out that voluntary participation particularly benefits people with mental health problems (cf. Binder, 2015; Binder \& Freytag, 2013). Moreover, nonpolitical and political participation may be both advantageous (Almedom, 2005; Berkman et al., 2000; Ferlander, 2007) and disadvantageous (Umberson \& Montez, 2010; Villalonga-Olives \& Kawachi, 2017), depending on the specific context. Both forms of participation may foster meaningful social roles, community attachment, and social support among group members, even if contacts with outgroup members are conflict ridden (Van Stekelenburg \& Klandermans, 2009). However, both forms of participation may also be perceived as burdensome, stressful, and socially confining (Son \& Wilson, 2012; Van Willigen, 2000). Such obstacles may be experienced if one is confronted with the suffering of others (e.g., during hospice volunteering; Claxton-Oldfield \& Claxton-Oldfield, 2012), or if organizations promote hierarchy between its members and restrict individual freedom (Ferlander, 2007; Villalonga-Olives \& Kawachi, 2017), which may apply to some religious and political organizations.

\subsection{Does Age Play a Role?}

In our main analyses, we found no support for the hypothesis that older adults benefit from nonpolitical participation more than younger age groups. Our post-hoc analyses showed that on occasions when older adults participated in any voluntary organization, they reported higher life satisfaction, better GHQ-12 scores, and more social support than when they did not. However, age differences in these effects were mostly not significant, which may be largely explained by the small effect sizes. Unexpectedly, on occasions when they reported political participation, only older adults reported significantly higher life satisfaction.

This positive effect and the overall lack of evidence on the negative consequences of political participation in older adults appears to contradict socioemotional selectivity theory because the presumable conflicts and hazards of political participation should be opposed to older adults' emotional and social needs (Carstensen et al., 1999; Theiss-Morse \& Hibbing, 2005). However, older adults may also remember and interpret situations and information more positively (positivity bias; Carstensen \& DeLiema, 2018) and react less negatively in situations of interpersonal tension (Luong \& Charles, 2014). Via these processes, older adults may be able to prevent or attenuate negative emotions in confrontational situations of political participation. Another theoretical explanation might be found in the concept of generativity (i.e., caring for the welfare of 
future generations; Erikson, 1950). As political participation is directed toward societal change, it enables individuals to act out their generative values (Serrat et al., 2017). However, prior research on generativity found only negligible age differences in generative concerns and actions (McAdams et al., 1993).

The only finding in favor of more beneficial effects of political participation in younger age groups was its significantly more positive association with contemporaneous neighborhood belonging in younger than in older adults. As they tend to avoid confrontation during conflicts (Holley et al., 2013), older adults may be less likely than younger adults to engage in organized resistance against perceived threats to the community (e.g., policy plans to build a highway near the neighborhood). However, the literature suggests that such collective opposition is a strong predictor of sense of community (Loomis et al., 2004; Perkins \& Long, 2002). Hence, predominantly younger but not older individuals may organize themselves against external threats toward the neighborhood, and the resulting political participation may, in turn, strengthen their neighborhood belonging.

\subsection{Limitations}

The limitations of this study largely pertain to the measures available in the BHPS and the UndSoc. Most notably, the dataset contained only binary measures of active participation in specific types of organizations (yes/no) but no information on time spent for participation or exact activities undertaken. Respondents who reported political participation might have performed direct helping activities, which may explain the discrepancy between our hypotheses and our findings. However, prior studies from other countries that did find differences in the effects of various types of participation (cf. Albanesi et al., 2007; Croezen et al., 2015; Lühr et al., 2021; Vinson \& Ericson, 2014; Yeung et al., 2018) could not consider exact activities either. Moreover, some of the measures or rating scales (e.g., life satisfaction) slightly differed between the BHPS and the UndSoc. We tried to adjust for this variation by including a survey indicator as a covariate at the within-person level. Furthermore, longitudinal attrition and missing data are a problem in many large-scale panel studies. We addressed these issues by using a full information estimator and adding missing data covariates.

Regarding our statistical approach, by modeling predictors and outcomes concurrently, we could not establish a direction of effects. Therefore, although we distinguished withinperson associations from between-person differences, our within-level results allow for no causal interpretation of effects. In post-hoc analyses, we modeled nonpolitical and political participation with a time lag of 1 year and found few significant effects on the outcome variables. The optimal time lag between predictor and outcome variable depends on their within-person stability (Dormann \& Griffin, 2015). Therefore, a time lag of 1 year may be a proper time lag for ascertaining effects on more stable outcomes, such as personality or neighborhood belonging. However, this interval may be too broad for detecting effects on emotional and psychological states (e.g., GHQ-12 scores) that vary more strongly within an individual over time (Mroczek et al., 2003). Optimal time lags are usually quite short, probably shorter than 1 year (Dormann \& Griffin, 2015), which is the shortest possible time lag in the BHPS/UndSoc and many other panel surveys. Therefore, we opted for the concurrent modeling of outcomes and predictors. Studies with shorter time lags than 1 year are preferable for investigating (lagged) effects of voluntary participation. 


\subsection{Conclusions and Future Directions}

In multilevel analyses with large-scale UK panel data, we found little evidence that older adults are more responsive to the mental health and social well-being benefits of voluntary participation than are younger adults. Although significant effects emerged mainly in older adults, they were negligible. Likewise, we found no support for the idea that nonpolitical participation is more beneficial than political participation. Nevertheless, future research should continue to explore on who benefits from nonpolitical and political participation in which context. First, positive effects of political participation may be mainly found in liberal political contexts, so cross-national differences in the effects of political participation should be investigated. Second, organizational structures and aims probably differ considerably even within nonpolitical and political organizations. More information on agendas of the specific organizations and participants' experiences within them are necessary to understand which exact organizations and activities benefit or impair mental health and social well-being of the participants. Third, voluntary participation may benefit specific subpopulations, such as people with mental health problems. Future research may investigate the benefits of voluntary participation in at-risk or clinical populations.

Supplementary Information The online version contains supplementary material available at https://doi. org/10.1007/s11205-021-02777-6.

Acknowledgements We thank John Wilson and Jane Piliavin for their helpful comments on the grant proposal that laid foundation for this study. The data (and tabulations) used in this study were made available through the UK Data Service. The British Household Panel Survey data were originally collected by the ESRC Research Centre on Micro-social Change at the University of Essex (now incorporated within the Institute for Social and Economic Research). Understanding Society is an initiative funded by the Economic and Social Research Council and various Government Departments, with scientific leadership by the Institute for Social and Economic Research, University of Essex, and survey delivery by NatCen Social Research and Kantar Public. Neither the original collectors of the data nor the UK Data Service bear any responsibility for the analyses or interpretations presented here.

Authors' Contributions Matthias Lühr: Conceptualization, Methodology, Formal Analysis, Writing - original draft, Writing - reviewing and editing, Visualization. Maria K. Pavlova: Conceptualization, Methodology, Writing - reviewing and editing, Supervision, Project administration, Funding acquisition. Maike Luhmann: Methodology, Writing - reviewing and editing, Supervision.

Funding Open Access funding enabled and organized by Projekt DEAL. This study was supported by the grant from the German Research Foundation (DFG) to the second author (PA 2704/3-1). The funding source had no influence on the design of this study, interpretation of its findings, manuscript preparation, and submission decision.

\section{Declarations}

Conflict of interest The authors certify that they have no affiliations with or involvement in any organization or entity with any financial interest or non-financial interest in the subject matter or materials discussed in this manuscript.

Data Availability The general data set used for this study is available at the UK Data Service. Reference: University of Essex, Institute for Social and Economic Research (2019). Understanding Society: Waves 1-8, 2009-2017 and Harmonised BHPS: Waves 1-18, 1991-2009. [Data collection]. 11th Edition. UK Data Service. SN:6614, http://doi.org/10.5255/UKDA-SN-6614-12. 
Open Access This article is licensed under a Creative Commons Attribution 4.0 International License, which permits use, sharing, adaptation, distribution and reproduction in any medium or format, as long as you give appropriate credit to the original author(s) and the source, provide a link to the Creative Commons licence, and indicate if changes were made. The images or other third party material in this article are included in the article's Creative Commons licence, unless indicated otherwise in a credit line to the material. If material is not included in the article's Creative Commons licence and your intended use is not permitted by statutory regulation or exceeds the permitted use, you will need to obtain permission directly from the copyright holder. To view a copy of this licence, visit http://creativecommons.org/licenses/by/4.0/.

\section{References}

Albanesi, C., Cicognani, E., \& Zani, B. (2007). Sense of community, civic engagement and social wellbeing in Italian adolescents. Journal of Community \& Applied Social Psychology, 17(5), 387-406. https://doi.org/10.1002/casp.903

Almedom, A. M. (2005). Social capital and mental health: An interdisciplinary review of primary evidence. Social Science \& Medicine, 61(5), 943-964. https://doi.org/10.1016/j.socscimed.2004.12. 025

Anderson, N. D., Damianakis, T., Kröger, E., Wagner, L. M., Dawson, D. R., Binns, M. A., Bernstein, S., Caspi, E., Cook, S. L., \& The BRAVO Team. (2014). The benefits associated with volunteering among seniors: A critical review and recommendations for future research. Psychological Bulletin, 140(6), 1505-1533. https://doi.org/10.1037/a0037610

Barbieri, P. N. (2017). The effect of social participation on self-rated physical and psychological well-being. Working paper in Economics 693, Department of Economics, University of Gothenburg, Gothenburg, Sweden.

Beauregard, K. (2014). Gender, political participation and electoral systems: A cross-national analysis. European Journal of Political Research, 53(3), 617-634. https://doi.org/10.1111/1475-6765.12047

Berkman, L. F., Glass, T., Brissette, I., \& Seeman, T. E. (2000). From social integration to health: Durkheim in the new millennium. Social Science \& Medicine, 51(6), 843-857.

Binder, M. (2015). Volunteering and life satisfaction: A closer look at the hypothesis that volunteering more strongly benefits the unhappy. Applied Economics Letters, 22(11), 874-885. https://doi.org/10.1080/ 13504851.2014.985364

Binder, M., \& Freytag, A. (2013). Volunteering, subjective well-being and public policy. Journal of Economic Psychology, 34, 97-119. https://doi.org/10.1016/j.joep.2012.11.008

Bjälkebring, P., Henning, G., Västfäll, D., Dickert, S., Brehmer, Y., Buratti, S., Hansson, I., \& Johansson, B. (2021). Helping out or helping yourself? Volunteering and life satisfaction across the retirement transition. Psychology and Aging, 36(1), 119-130. https://doi.org/10.1037/pag0000576

Carstensen, L. L., \& DeLiema, M. (2018). The positivity effect: A negativity bias in youth fades with age. Current Opinion in Behavioral Sciences, 19, 7-12. https://doi.org/10.1016/j.cobeha.2017.07.009

Carstensen, L. L., Isaacowitz, D. M., \& Charles, S. T. (1999). Taking time seriously. A theory of socioemotional selectivity. American Psychologist, 54(3), 165-181. https://doi.org/10.1037//0003-066X.54.3. 165

Claxton-Oldfield, S., \& Claxton-Oldfield, J. (2012). Should I stay or should I go: A study of hospice palliative care volunteer satisfaction and retention. American Journal of Hospice and Palliative Medicine, 29(7), 525-530. https://doi.org/10.1177/1049909111432622

Community Works. (n.d.). Volunteering and mental health. https://www.bhcommunityworks.org.uk/volun tary-sector/volunteering/good-practice-guide/inclusion/volunteering-and-mental-health/

Croezen, S., Avendano, M., Burdorf, A., \& van Lenthe, F. J. (2015). Social participation and depression in old age: A fixed-effects analysis in 10 European countries. American Journal of Epidemiology, 182(2), 168-176. https://doi.org/10.1093/aje/kwv015

Dawson-Townsend, K. (2019). Social participation patterns and their associations with health and wellbeing for older adults. SSM - Population Health, 8, 100424. https://doi.org/10.1016/j.ssmph.2019. 100424

De Wit, A., Bekkers, R., Karamat Ali, D., \& Verkaik, D. (2015). Welfare impacts of participation. [Deliverable 3.3 of the project: "Impact of the Third Sector as Social Innovation" (ITSSOIN), European Commission - 7th Framework Programme, Brussels: European Commission, DG Research].

Dormann, C., \& Griffin, M. A. (2015). Optimal time lags in panel studies. Psychological Methods, 20(4), 489-505. https://doi.org/10.1037/met0000041 
Douglas, H., Georgiou, A., \& Westbrook, J. (2017). Social participation as an indicator of successful aging: An overview of concepts and their associations with health. Australian Health Review, 41(4), 455-462. https://doi.org/10.1071/AH16038

Erikson, E. H. (1950). Childhood and society. W. W. Norton and Company Inc.

Esping-Andersen, G. (1990). The three worlds of welfare capitalism. Princeton University Press.

Ferlander, S. (2007). The importance of different forms of social capital for health. Acta Sociologica, 50(2), 115-128. https://doi.org/10.1177/0001699307077654

Fiorillo, D., Lavadera, G. L., \& Nappo, N. (2017). Social participation and self-rated psychological health: A longitudinal study on BHPS. SSM - Population Health, 3, 266-274. https://doi.org/10.1016/j.ssmph. 2017.02.003

Giordano, G. N., \& Lindström, M. (2011). Social capital and change in psychological health over time. Social Science \& Medicine, 72(8), 1219-1227. https://doi.org/10.1016/j.socscimed.2011.02.029

Goldberg, D., \& Williams, P. (1988). A user's guide to the General Health Questionnaire. NFER-Nelson.

Gray, A. (2009). The social capital of older people. Ageing and Society, 29(1), 5-31. https://doi.org/10. 1017/S0144686X08007617

Hamaker, E. L., \& Muthén, B. (2020). The fixed versus random effects debate and how it relates to centering in multilevel modeling. Psychological Methods, 25(3), 365-379. https://doi.org/10.1037/ met0000239

Hansard Society. (2019). Audit of political engagement 16. The 2019 report. https://www.hansardsociety. org.uk/publications/reports/audit-of-political-engagement-16

Hansen, T., Aartsen, M., Slagsvold, B., \& Deindl, C. (2018). Dynamics of volunteering and life satisfaction in midlife and old age: Findings from 12 European countries. Social Sciences, 7(5), 78. https:// doi.org/10.3390/socsci7050078

Haski-Leventhal, D. (2009). Elderly volunteering and well-being: A cross-European comparison based on SHARE data. VOLUNTAS: International Journal of Voluntary and Nonprofit Organizations, 20(4), 388-404. https://doi.org/10.1007/s11266-009-9096-x

Health Education England. (2017). Volunteering strategy 2017. Consultation document. https://www. hee.nhs.uk/sites/default/files/documents/13707\%20HEE\%20Volunteering\%20Strategy\%20Doc ument_June $\% 202017 \% 20$ web.pdf

Holley, S. R., Haase, C. M., \& Levenson, R. W. (2013). Age-related changes in demand-withdraw communication behaviors: Demand-withdraw and aging. Journal of Marriage and Family, 75(4), 822836. https://doi.org/10.1111/jomf.12051

Keyes, C. L. M. (2006). Subjective well-being in mental health and human development research worldwide: An introduction. Social Indicators Research, 77(1), 1-10. https://doi.org/10.1007/ s11205-005-5550-3

Knol, M. J., Pestman, W. R., \& Grobbee, D. E. (2011). The (mis)use of overlap of confidence intervals to assess effect modification. European Journal of Epidemiology, 26(4), 253-254. https://doi.org/10. 1007/s10654-011-9563-8

Lawton, R. N., Gramatki, I., Watt, W., \& Fujiwara, D. (2020). Does volunteering make us happier, or are happier people more likely to volunteer? Addressing the problem of reverse causality when estimating the wellbeing impacts of volunteering. Journal of Happiness Studies, 22(11), 599-624. https:// doi.org/10.1007/s10902-020-00242-8

Li, Y., \& Ferraro, K. F. (2005). Volunteering and depression in later life: Social benefit or selection processes? Journal of Health and Social Behavior, 46(1), 68-84. https://doi.org/10.1177/0022146505 04600106

Li, Y., Pickles, A., \& Savage, M. (2005). Social capital and social trust in Britain. European Sociological Review, 21(2), 109-123. https://doi.org/10.1093/esr/jci007

Lombardo, P., Jones, W., Wang, L., Shen, X., \& Goldner, E. M. (2018). The fundamental association between mental health and life satisfaction: Results from successive waves of a Canadian national survey. BMC Public Health, 18(1), 342. https://doi.org/10.1186/s12889-018-5235-x

Loomis, C., Dockett, K. H., \& Brodsky, A. E. (2004). Change in sense of community: An empirical finding. Journal of Community Psychology, 32(1), 1-8. https://doi.org/10.1002/jcop.10081

Luong, G., \& Charles, S. T. (2014). Age differences in affective and cardiovascular responses to a negative social interaction: The role of goals, appraisals, and emotion regulation. Developmental Psychology, 50(7), 1919-1930. https://doi.org/10.1037/a0036621

Lühr, M., Pavlova, M. K., \& Luhmann, M. (2021). They are doing well, but is it by doing good? Longitudinal associations of nonpolitical and political volunteering with three dimensions of well-being in age comparison. Unpublished manuscript

Manwell, L. A., Barbic, S. P., Roberts, K., Durisko, Z., Lee, C., Ware, E., \& McKenzie, K. (2015). What is mental health? Evidence towards a new definition from a mixed methods multidisciplinary 
international survey. BMJ Open, 5(6), e007079-e007079. https://doi.org/10.1136/bmjop en-2014-007079

Mazhari, L. (2015). The pursuit of happiness: The effect of social involvement on life satisfaction in Canada. The Arbutus Review, 6(1), 76-100. https://doi.org/10.18357/ar.mazharil.612015

McAdams, D. P., St Aubin, E. D., \& Logan, R. L. (1993). Generativity among young, midlife, and older adults. Psychology and Aging, 8(2), 221-230. https://doi.org/10.1037/0882-7974.8.2.221

McLaughlin, K. A. (2011). The public health impact of major depression: A call for interdisciplinary prevention efforts. Prevention Science, 12(4), 361-371. https://doi.org/10.1007/s11121-011-0231-8

McMillan, D. W., \& Chavis, D. M. (1986). Sense of community: A definition and theory. Journal of Community Psychology, 14(1), 6-23. https://doi.org/10.1002/1520-6629(198601)14:1\%3c6::AIDJCOP2290140103\%3e3.0.CO;2-I

Meier, S., \& Stutzer, A. (2008). Is volunteering rewarding in itself? Economica, 75(297), 39-59. https:// doi.org/10.1111/j.1468-0335.2007.00597.x

Morrow-Howell, N. (2010). Volunteering in later life: Research frontiers. The Journals of Gerontology, Series B: Psychological Sciences and Social Sciences, 65(4), 461-469. https://doi.org/10.1093/geronb/ gbq024

Mroczek, D. K., Spiro, A., \& Almeida, D. M. (2003). Between- and within-person variation in affect and personality over days and years: How basic and applied approaches can inform one another. Ageing International, 28(3), 260-278. https://doi.org/10.1007/s12126-002-1007-z

Musick, M. A., \& Wilson, J. (2003). Volunteering and depression: The role of psychological and social resources in different age groups. Social Science \& Medicine, 56(2), 259-269. https://doi.org/10.1016/ S0277-9536(02)00025-4

Muthén, B., \& Asparouhov, T. (2012). Bayesian structural equation modeling: A more flexible representation of substantive theory. Psychological Methods, 17(3), 313-335. https://doi.org/10.1037/a0026802

Newman, D. A. (2003). Longitudinal modeling with randomly and systematically missing data: A simulation of ad hoc, maximum likelihood, and multiple imputation techniques. Organizational Research Methods, 6(3), 328-362. https://doi.org/10.1177/1094428103254673

Okun, M. A., \& Schultz, A. (2003). Age and motives for volunteering: Testing hypotheses derived from socioemotional selectivity theory. Psychology and Aging, 18(2), 231-239. https://doi.org/10.1037/ 0882-7974.18.2.231

Pavlova, M. K., Gellerman, J. M., Holtmann, E., Jaeck, T., Körner, A., \& Silbereisen, R. K. (2021). Applying the volunteer process model to predict future intentions for civic and political participation. Same antecedents, different experiences? Journal of Social Psychology. https://doi.org/10.1080/00224545. 2021.1953957

Pavlova, M. K., \& Silbereisen, R. K. (2012). Participation in voluntary organizations and volunteer work as a compensation for the absence of work or partnership? Evidence from two German samples of younger and older adults. The Journals of Gerontology, Series B: Psychological Sciences and Social Sciences, 67(4), 514-524. https://doi.org/10.1093/geronb/gbs051

Perkins, D. D., \& Long, D. A. (2002). Neighborhood sense of community and social capital: A multilevel analysis. In A. T. Fisher, C. C. Sonn, \& B. J. Bishop (Eds.), Psychological sense of community: Research, applications, and implications (pp. 291-318). Plenum. https://doi.org/10.1007/978-1-46150719-2_15

Piliavin, J. A., \& Siegl, E. (2015). Health and well-being consequences of formal volunteering. In D. A. Schroeder \& W. G. Graziano (Eds.), The Oxford handbook of prosocial behavior (pp. 494-523). Oxford University Press.

Pilkington, P. D., Windsor, T. D., \& Crisp, D. A. (2012). Volunteering and subjective well-being in midlife and older adults: The role of supportive social networks. The Journals of Gerontology, Series B: Psychological Sciences and Social Sciences, 67(2), 249-260. https://doi.org/10.1093/geronb/gbr154

Ruiter, S., \& De Graaf, N. D. (2009). Socio-economic payoffs of voluntary association involvement: A Dutch life course study. European Sociological Review, 25(4), 425-442. https://doi.org/10.1093/esr/ jen051

Russell, A. R., Nyame-Mensah, A., de Wit, A., \& Handy, F. (2019). Volunteering and wellbeing among ageing adults: A longitudinal analysis. VOLUNTAS: International Journal of Voluntary and Nonprofit Organizations, 30(1), 115-128. https://doi.org/10.1007/s11266-018-0041-8

Serrat, R., Villar, F., Warburton, J., \& Petriwskyj, A. (2017). Generativity and political participation in old age: A mixed method study of Spanish elders involved in political organisations. Journal of Adult Development, 24(3), 163-176. https://doi.org/10.1007/s10804-016-9255-4

Son, J., \& Wilson, J. (2012). Volunteer work and hedonic, eudemonic, and social well-being. Sociological Forum, 27(3), 658-681. https://doi.org/10.1111/j.1573-7861.2012.01340.x 
Spicker, P. (2013). Liberal welfare states. In B. Greve (Ed.), The Routledge Handbook of the Welfare State (pp. 193-201). Routledge.

Tabassum, F., Mohan, J., \& Smith, P. (2016). Association of volunteering with mental well-being: A lifecourse analysis of a national population-based longitudinal study in the UK. BMJ Open, 6(8), e011327. https://doi.org/10.1136/bmjopen-2016-011327

Talò, C., Mannarini, T., \& Rochira, A. (2014). Sense of community and community participation: A metaanalytic review. Social Indicators Research, 117(1), 1-28. https://doi.org/10.1007/s11205-013-0347-2

Taylor, M. F., Brice, J., Buck, N., \& Prentice-Lane, E. (2010). British Household Panel Survey user manual volume A: Introduction, technical report and appendices. Colchester: University of Essex.

Theiss-Morse, E., \& Hibbing, J. R. (2005). Citizenship and civic engagement. Annual Review of Political Science, 8(1), 227-249. https://doi.org/10.1146/annurev.polisci.8.082103.104829

Thoits, P. A., \& Hewitt, L. N. (2001). Volunteer work and well-being. Journal of Health and Social Behavior, 42(2), 115-131. https://doi.org/10.2307/3090173

University of Essex, Institute for Social and Economic Research. (2019). Understanding Society: Waves 1-8, 2009-2017 and Harmonised BHPS: Waves 1-18, 1991-2009. [Data collection]. 11th Edition. UK Data Service. SN:6614. https://doi.org/10.5255/UKDA-SN-6614-12

Umberson, D., \& Montez, J. K. (2010). Social relationships and health: A flashpoint for health policy. Journal of Health and Social Behavior, 51(Suppl), S54-S66. https://doi.org/10.1177/0022146510383501

Van Ingen, E., \& Kalmijn, M. (2010). Does voluntary association participation boost social resources? Social Science Quarterly, 91(2), 493-510. https://doi.org/10.1111/j.1540-6237.2010.00704.x

Van Stekelenburg, J., \& Klandermans, P. G. (2009). Social movement theory: Past, present, and prospect. In I. Van Kessel \& S. Ellis (Eds.), Movers and shakers: Social movements in Africa (pp. 17-44). Brill.

Van Willigen, M. (2000). Differential benefits of volunteering across the life course. The Journals of Gerontology, Series B: Psychological Sciences and Social Sciences, 55(5), S308-S318. https://doi.org/10. 1093/geronb/55.5.S308

Verba, S., Schlozman, K. L., \& Brady, H. E. (1995). Voice and equality. Civic voluntarism in American politics. Havard University Press.

Villalonga-Olives, E., \& Kawachi, I. (2017). The dark side of social capital: A systematic review of the negative health effects of social capital. Social Science \& Medicine, 194, 105-127. https://doi.org/10. 1016/j.socscimed.2017.10.020

Vinson, T., \& Ericson, M. (2014). The social dimensions of happiness and life satisfaction of Australians: Evidence from the World Values Survey. International Journal of Social Welfare, 23(3), 240-253. https://doi.org/10.1111/ijsw.12062

Wang, L. P., \& Maxwell, S. E. (2015). On disaggregating between-person and within-person effects with longitudinal data using multilevel models. Psychological Methods, 20(1), 63-83. https://doi.org/10. $1037 /$ met0000030

Wilson, J. (2012). Volunteerism research: A review essay. Nonprofit and Voluntary Sector Quarterly, 41(2), 176-212. https://doi.org/10.1177/0899764011434558

Winters, M. S., \& Rundlett, A. (2014). The challenges of untangling the relationship between participation and happiness. VOLUNTAS: International Journal of Voluntary and Nonprofit Organizations, 26(1), 5-23. https://doi.org/10.1007/s11266-014-9500-z

World Health Organization. (2018). Mental health: Strengthening our response. https://www.who.int/newsroom/fact-sheets/detail/mental-health-strengthening-our-response

Xue, X., Reed, W. R., \& Menclova, A. (2020). Social capital and health: A meta-analysis. Journal of Health Economics, 72, 102317. https://doi.org/10.1016/j.jhealeco.2020.102317

Yeung, J. W. K., Zhang, Z., \& Kim, T. Y. (2018). Volunteering and health benefits in general adults: Cumulative effects and forms. BMC Public Health, 18(1), 8. https://doi.org/10.1186/s12889-017-4561-8

Publisher's Note Springer Nature remains neutral with regard to jurisdictional claims in published maps and institutional affiliations. 